\title{
Biohydrogen Production by Reusing Immobilized Mixed Culture in Batch System
}

\author{
Astrilia Damayanti ${ }^{\mathrm{a}}$, Sarto $^{\mathrm{b}}$, and Wahyudi Budi Sediawan ${ }^{\mathrm{b}}$ \\ ${ }^{a}$ Department of Chemical Engineering, Universitas Negeri Semarang, Kampus Sekaran, Gunungpati, Semarang, Indonesia \\ ${ }^{b}$ Department of Chemical Engineering Universitas Gadjah Mada, Yogyakarta, Indonesia
}

\begin{abstract}
Biohydrogen production via dark fermentation is a prospective renewable energy technology. In the process, reused of immobilized mixed culture is very important as their activities greatly influence hydrogen production. The aim of this work was to evaluate the reuse of alginate beads affecting the biohydrogen production for 45 days. This study in batch reactor were performed using glucose $10 \mathrm{M}$ as substrate, alginate and activated carbon as immobilization matrix materials, chicken eggshell as buffer, and cow dung biodigester as mixed culture. Hydrogen and $\mathrm{pH}$ on fermentation product are investigated by gas chromatography (GC) technique and $\mathrm{pH}$ meter, respectively. The colony diameter on immobilized and co-immobilized mixed culture was observed using optical microscope and colony diameter was measured using Image-Pro Plus Software v4.5.0.29. The surface morphology of immobilization and coimmobilization beads were determined using scanning electron microscope (SEM). The results showed that the colonies growth observed using optical microscopy or SEM was apparent only in the immobilization of mixed culture. The average growth and diameter of colonies per day were 90 colonies and $0.025 \mathrm{~mm}$, respectively. The weight of beads and $\mathrm{pH}$ during the 45 -day fermentation process for bead immobilization of mixed culture were $1.32-1.95 \mathrm{~g}$ and $6.25-6.62$, correspondingly, meanwhile, the co-immobilizations of the mixed culture were $1.735-2.21 \mathrm{~g}$ and $6.25-6.61$, respectively. In addition, the average hydrogen volume of glucose fermented using an eggshell buffer and reusing the immobilization and co-immobilization beads was $18.91 \mathrm{~mL}$ for 15 cycles. O2020. CBIORE-IJRED. All rights reserved
\end{abstract}

Keywords: biohydrogen; reused beads; immobilization; mixed culture; batch

Article History: Received: June 16, 2019; Revised: November 17, 2019; Accepted: January 16, 2020; Available online: February 15, 2020

How to Cite This Article: : Damayanti, A., Sarto, Sediawan, W.B. (2020), Biohydrogen Production by Reusing Immobilized Mixed Culture in Batch System. International Journal of Renewable Energy Development, 9(1), 37-42 https://doi.org/10.14710/ijred.9.1.37-42

\section{Introduction}

The identification of an alternative energy is challenging given the depletion of fossil fuels amount. This depletion was due to energy demand which has increased along with the human population and the combustion effects of greenhouse gases that have caused global climate change. One of potential renewable and non-polluting alternative energies to be developed is hydrogen (Penniston and Kana 2018; Akil and Jayanthi 2015; Reyhani and Zilouei 2013). In addition, hydrogen has the highest heating value (143 GJ/ton) among the sources of energy (Das 2009).

The most common biohydrogen is produced through dark fermentation technology because its temperatures and pressure can be conducted moderately (Akil and Jayanthi 2015). Moreover, the production of biohydrogen uses minimal energy input (Sekoai et al. 2017). The use of naturally mixed culture for hydrogen fermentation production offers numerous advantages over single culture considering the metabolic flexibility and robustness of the former process (Wang et al. 2017). An acid pre-treatment method was used to prepare considerable anaerobic hydrogen-producing microbial from natural sources (Cai and Wang 2016; Cheong et al. 2006). In addition, this method also reported to help suppress the methanogenic bacteria activity (Saripan and Reungsang 2014). Furthermore, an enriched (natural) mixed culture was used to enhance the yield and production rate of hydrogen (Sivagurunathan et al. 2014).

The use of immobilized cell systems in developing a biohydrogen process development has several advantages over suspended cell systems. These advantages include improved handling (Penniston and Kana 2018), resistant to cell washout, production of enhanced yields, and reusability (Sekoai, Yoro, and Daramola 2016). Technology by entrapping cells in a solid matrix through dripping extrusion is a common approach to immobilising cells.

Alginate is a natural polysaccharide and is preferred as an immobilising microorganism considering its high transparency ( $\mathrm{Ng}$ et al. 2017), nontoxicity (Hassan et al. 2014) and ability to live within small holes (Covarrubias et al. 2012).However, alginate beads have weak mechanical stability because they do not retain their structure at high cation concentrations $\left(\mathrm{K}^{+}, \mathrm{Ca}^{2+}\right.$ and $\mathrm{Mg}^{2+}$ )(Sekoai et al. 2017). Co-immobilized activated 
carbon (AC) in alginate is a technique that improves mechanical strength (Mesran et al. 2014). AC is an immobilization carrier and has been well-documented as a support matrix in dark fermentation (Zhang et al. 2017). AC has a high specific surface area and low toxicity. Its character sustains cell viability, where a fermentative inoculum can grow freely inside a porous structure on the surface (Zhang et al. 2017)(Jamali et al. 2016). Highly porous structure and the surface, where the bacteria can grow freely, sustain cell viability and enhance cell density (Zhang et al. 2017) (Jamali et al. 2016). The simultaneous use of two or more matrix materials is called co-immobilization (Siahpush et al. 1992).

Biohydrogen generation through dark fermentation is largely depends on $\mathrm{pH}$ level, as the $\mathrm{pH}$ affects enzyme activities and metabolite transport (Davila-Vazquez et al. 2011). Moreover, it determines product distribution during fermentation (Muñoz-Páez et al. 2014). A low pH can inhibit hydrogen-consuming methanogenic microorganisms (Wu, Yao, and $\mathrm{Zhu} 2010$ ) given the generation of organic acids (Zhu et al. 2009). An alternative is to add sufficient buffer materials or bicarbonate. A natural bicarbonate can be obtained from chicken eggshell which contains $93.6 \% \mathrm{CaCO}_{3}$ (Neunzehn et al.2015)

A material requirement for cell immobilization is suitable for cell regeneration (Dzionek et al. 2016). Hydrogen is mainly produced during cell growth (Luo et al. 2010). Therefore, the major objective of this study is to evaluate the gel strength of mixed culture immobilization and co-immobilization (Shoichet et al. 1996) on anaerobic biohydrogen using reused beads, a new medium and chicken eggshell. Furthermore, the size and amount of microbial growth in immobilization and coimmobilization were used to describe the hydrogen production. In addition, the $\mathrm{pH}$ and bead weight were evaluated during the fermentation.

\section{Materials and Methods}

\subsection{Anaerobic mixed culture and pre-treatment}

An anaerobic mixed culture obtained from cow dung biodigester (3.6 g VSS/l), Yogyakarta, Indonesia, was used as the inoculum. The inoculum $(150 \mathrm{ml})$ was subjected to acid treatment by adjusting $\mathrm{pH}$ to 3 using 2M HCl (Merck, 37\%)and maintained under anaerobic conditions for $24 \mathrm{~h}$. Subsequently, the $\mathrm{pH}$ of acid pretreated mixed culture was re-adjusted to 6 using $2 \mathrm{M}$ $\mathrm{NaOH}$.

\subsection{Enrichment of hydrogen-producing mixed culture}

Enrichment of hydrogen producing mixed cultures was conducted in $100 \mathrm{~mL}$ serum vials with $45 \mathrm{~mL}$ working volume. The pre-reduced anaerobically sterilized peptone-yeast extract-glucose (PYG) medium contained the following nutrients (in $\mathrm{g} / \mathrm{L}$ ): 10 glucose, 10 yeast extract, 10 peptones, 0.5 L-cysteine-HCl, and 0.001 resazurin. Mixed culture $2 \mathrm{ml}$ was fed to a PYG medium bottle and then incubated for 24 hours. This method was repeated thrice. The final enriched mixed culture was used as an inoculum for the fermentation experiments.

\subsection{Substrate and Medium composition}

The medium composition consisted of $10 \mathrm{~g} / \mathrm{L}$ peptone, 10 $\mathrm{g} / \mathrm{L}$ yeast extract, 0,001 $\mathrm{g} / \mathrm{L}$ resazurin, and $0,5 \mathrm{~g} / \mathrm{L} \mathrm{L}$ cysteine- $\mathrm{HCl}$. The substrate was $10 \mathrm{~g} / \mathrm{L}$ glucose,

\subsection{Immobilized and co-immobilized mixed culture}

Immobilized material characteristics was similar to those in the previous experiment (Damayanti et al. 2018). Two grams of alginate was dissolved in $100 \mathrm{~mL}$ distilled water. The ratio of Alginate concentration to AC was 1:1. The preparation of immobilized and co-immobilized mixed culture was similar to that in the previous experiment (Damayanti et al. 2018)

\subsection{Buffer from Chicken Eggshell}

Powder of eggshells approximately $3.2 \mathrm{~g}$ dry weight was added into the fermentor. The chicken eggshell was prepared in accordance with the previous experiment (Damayanti et al., 2017).

\subsection{Biohydrogen Production Process}

The dependent variables studied include total gas produced, amount of hydrogen, weight beads, and size of colony diameter. Two sets of fermentation processes were conducted in a $100-\mathrm{mL}$ serum vial with $50 \mathrm{~mL}$ working volume under a sterile and anaerobic condition at $37^{\circ} \mathrm{C}$. The reactors were fed with $30 \%(\mathrm{v} / \mathrm{v})$ substrate, $60 \%$ (v/v) medium and $10 \%(\mathrm{v} / \mathrm{v})$ mixed culture. The bead weight and hydrogen-producing consortia of immobilization were three $\mathrm{g}$ and $0.3945 \mathrm{~g} . \mathrm{L}^{-1}$, respectively, whereas $3.5 \mathrm{~g}$ and 0.635 g. $\mathrm{L}^{-1}$ for co-immobilization. Chicken eggshell, substrate, and medium were sterilised by autoclaving at $121{ }^{\circ} \mathrm{C}$ for $15 \mathrm{~min}$.

The biohydrogen was processed through fermentation for three days per cycle or run. New glucose substrate and eggshell were used, but immobilization and co-immobilization materials were reused.

Hydrogen production was performed in batch system using glucose substrate, beads, and eggshell. The eggshell, immobilized and co-immobilized beads were required, similar to the previous experiment (Damayanti et al. 2017). The reactor and fermentation were conducted anaerobically (Damayanti et al. 2017). Each fermentation was rendered for three days. However, on the third day, the substrate was replaced, and the bead was restored. The process was performed for 45 days, and sampling was conducted in duplicate.

\subsection{Visualization of colonization by optical microscopes and scanning electron microscope (SEM)}

The measurement of colony diameter on immobilized and co-immobilized mixed culture was observed using an optical microscope (Celestron 44348 Pentaview Digital Microscope, China). Then, colony diameter was measured using Image-Pro Plus Software v4.5.0.29. A $0.112 \mathrm{~mm}$ cable was used as a standard. Furthermore, the actual colony diameter was calculated using MS Excel.

The surface morphology of immobilization and coimmobilization beads was observed using an SEM (JOEL, JEM-1200EX, Japan) at the magnification of 500 times. Colony observations on immobilization and co- 
immobilization beads were initiated by fixation in a Bunsen flame and then coated with platinum. The samples were observed under an SEM (JOEL, JEM1200EX, Japan).

\subsection{Analytical methods}

Hydrogen was analysed using gas chromatography (GC). Shimadzu GC 8A (Japan) equipped with a thermal conductivity detector (TCD) and molecular column sieve $5 \mathrm{~A}$ (MS-5A) with 5m column length. Temperature of column, detector, and injector were set at $60^{\circ} \mathrm{C}, 70^{\circ} \mathrm{C}$, and $70^{\circ} \mathrm{C}$, sequentially. Nitrogen was used as carrier gas with an inlet pressure of $100 \mathrm{kPa}$. The $\mathrm{pH}$ of the sample during the fermentation process was measured using a Lutron PH-208 pH meter that was calibrated with buffer solution $\mathrm{pH} 7$.

\section{Results and Discussion}

\subsection{Colonies growth in immobilized and co-immobilized mixed culture}

Observations of colony growth under immobilized and coimmobilized mixed culture conditions using optical microscopy were presented in Figures 1 and 2.
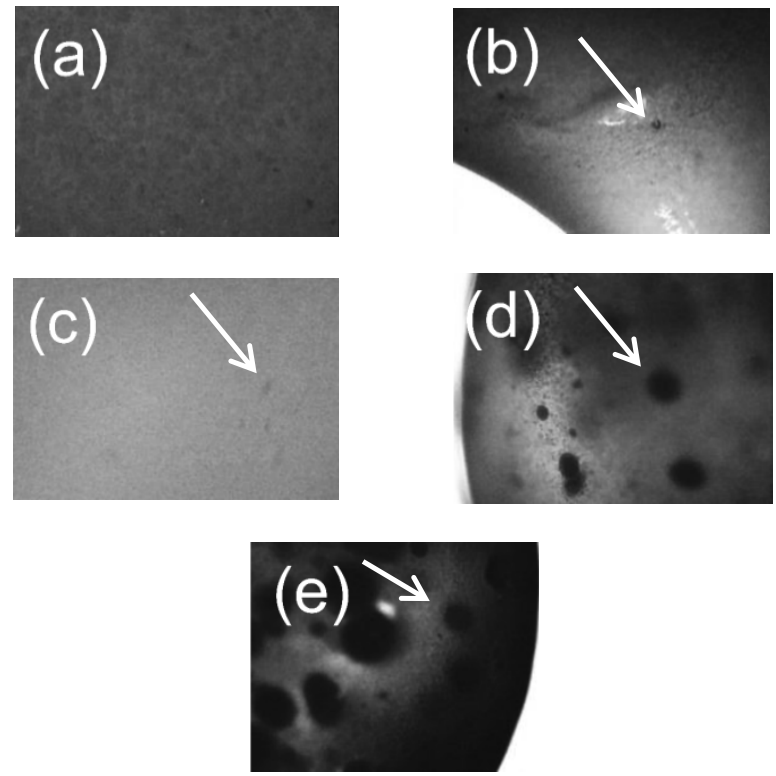

Fig.1. Growth of colonies on immobilized mixed culture observed using optical microscope (a) on zero-day at 100 times magnification, (b) on the $3^{\text {rd }}$ day at 100x magnification, (c) on the $9^{\text {th }}$ day at 100 times magnification, (d) on the $18^{\text {th }}$ day, and (e) on the $21^{\text {st }}$ day at 40 times magnification, respectively.

Figure 1 illustrates the growth of colonies on the surface beads of immobilized mixed culture. Starting with Figure 1a, taken on day 0, only a few or almost no colony could be seen as it was the beginning. Observation was continued on the third-day and ninth-day (Figures $1 \mathrm{~b}$ and 1c) and images obtained shows that the colonies started to grow. Until the $18^{\text {th }}$ and $21^{\text {st }}$ day, the development of the number of colonies was increasingly seen as can be seen in Figures 1d and 1e. This shows that the colony in this experiment can grow continuously even with a slow speed.

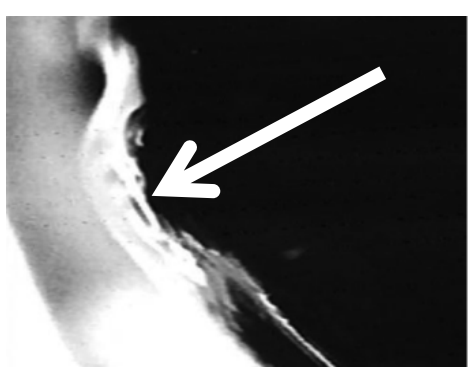

Fig.2. Co-immobilized mixed culture on $36^{\text {th }}$ day, observed using optical microscope using 40 times magnification.

Figure 2 demonstrates that alginate was found in the outermost layer of the beads and in a black colour. This result was similar to that obtained by Mesran et al. (2014). The microorganism colonies in the form of a circle represent an aggregation of microorganisms as the result of alginate adsorption (Alonso et al. 2015). The diameter and number of colonies at a certain time are showed in Figure 3.

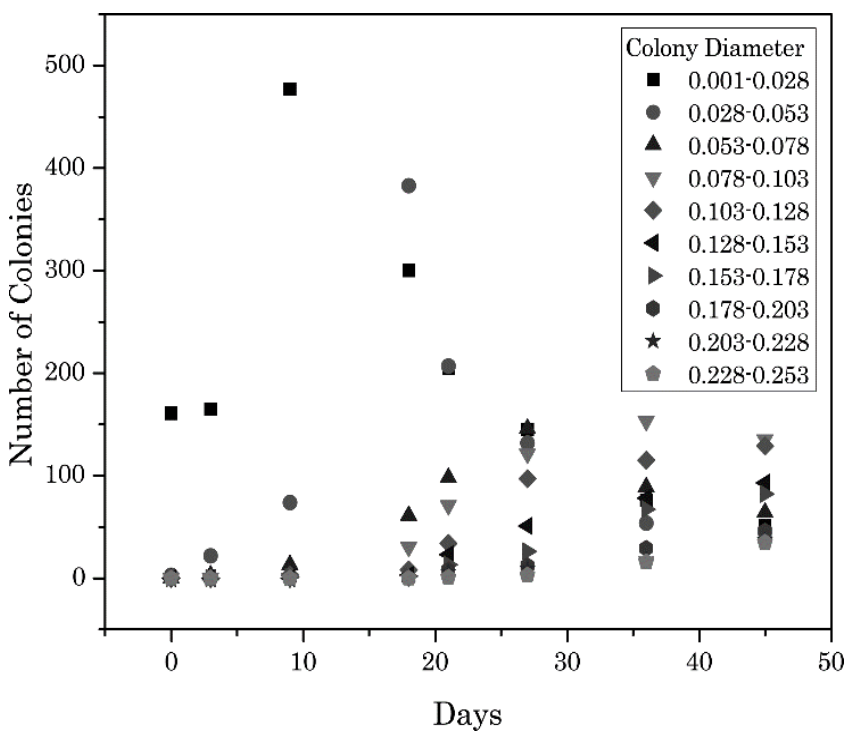

Fig.3. Profile of diameter and number of the colonies

Figure 3 presents that the indicators of colonisation growth include an extensive fermentation period and an increase in the number of colonies. The phenomenon of colony growth in immobilization and co-immobilization was due to the size of glucose $(2,845 \mathrm{~nm}$ [ChemSketch software]) which was twice smaller than the pore size of alginate beads (5-200 nm) (Alonso et al. 2015). Thus, glucose was easily entered the pores of alginate beads and consumed by the bacteria. The morphology of beads with and without the colonies on day 0 and day $18^{\text {th }}$ of fermentation for immobilized and co-immobilized beads was observed using the SEM (Figures 4 and 5). 


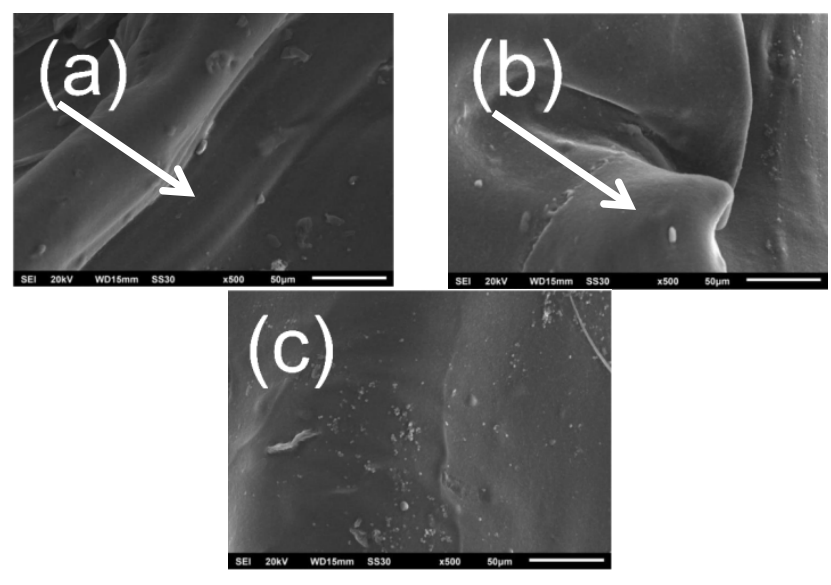

Fig.4. Morphology of SEM at 500 times magnification for immobilized beads (a) without colonies, (b) with colonies on day zero, (c) with colonies on $18^{\text {th }}$ fermentation day

Figure 4 depicts that the growth of colonies is characterized by spherical protuberances on the surface of immobilized mixed culture from Day 0 (Figure $4 \mathrm{~b}$ ) to Day $18^{\text {th }}$ (Figure 4c) in comparison with immobilized mixed culture without microorganisms (Figure 4a). The spherical protuberances are the colonies of microorganisms found in immobilized beads of many cavities that were used with the increase in microorganisms. These cavities were also the result of immobilization processes and serve as a physical separator between inhibitors and microorganisms (Covarrubias et al. 2012).

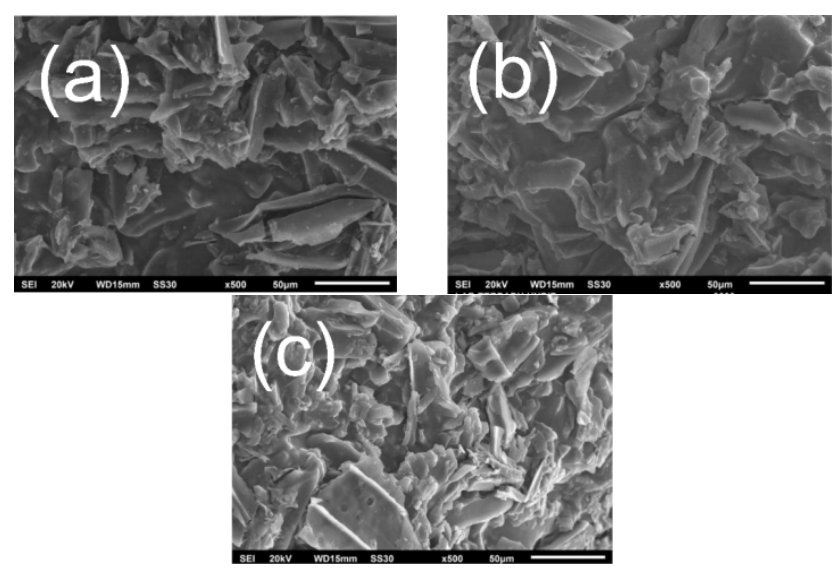

Fig. 5. Morphology of SEM at 500 times magnification for coimmobilized beads (a) without colonies, (b) with colonies on day zero, (c) with colonies on $39^{\text {th }}$ fermentation day

Moreover, Figure 3 illustrates the surface of the immobilized mixed culture which is a rigid and solid layer that serves as the ultimate protection for microorganisms (Covarrubias et al. 2012). This type of surface was produced instantaneously whilst the alginate liquid drops into the cation-binding solution (e.g. $\mathrm{CaCl}_{2}$ in this study) during polymerisation (Smidsrød and Skjåk-Braek 1990). This process was called an entrapment that causes more cavities beneath the surface layer than inside the beads (Zohar-Perez et al.
2004). Simultaneously, the shrinking surface layer processes of the beads caused the occurrence of spherical protuberances (Covarrubias et al. 2012).

Figure 5 demonstrates that the presence of microorganisms in colonies at the co-immobilization beads could not be acknowledged clearly. The structure of $\mathrm{AC}$ appears to be increasingly dominant. The coimmobilization in this study was similar to that obtained by Mesran et al. (2014), that is, the microorganisms were found in an $\mathrm{AC}$ hole.

\subsection{Comparison of weight beads between immobilized and co-immobilized beads}

Beads were reused to determine the weight of immobilization and co-immobilization beads during fermentation, as presented in Figure 6.

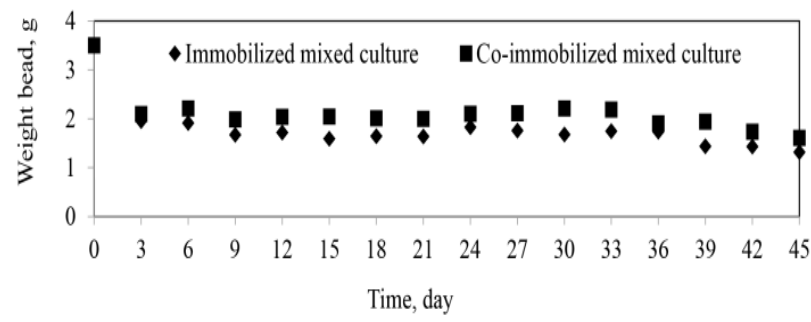

Fig. 6. Beads weight during the fermentation process

Figure 6 shows that the bead weights decreased on Day 3. However, the weight loss was greater in the immobilized mixed culture than in the co-immobilized mixed culture, thereby demonstrating that $\mathrm{AC}$ acts as an alginate buffer (Wu et al. 2002). The weight loss of immobilized and co-immobilized mixed culture was caused by the broken beads. Statistical analysis using single factor analysis reports p-value of 0.05167 which means $p$-value $>0.05$. This number means that the difference in material (immobilized and co-immobilized) does not make a significant difference in the weight of the bead obtained.

\subsection{Comparison of $p H$ between immobilized and co- immobilized beads}

The level of acidity $(\mathrm{pH})$ during fermentation using the reused beads for immobilized and co-immobilized beads was obtained, as exhibited in Figure 7.

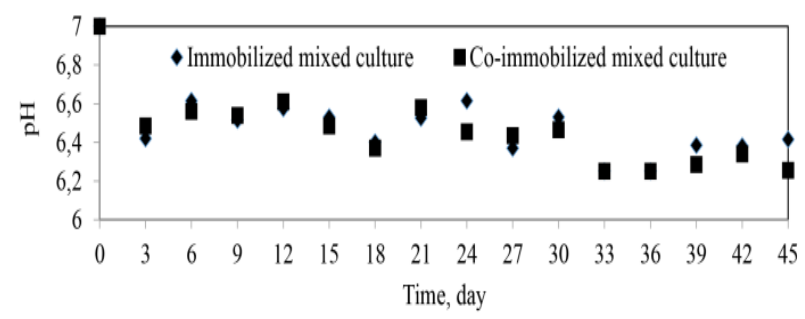

Fig. 7. $\mathrm{pH}$ solution during the fermentation process

Figure 7 shows that the $\mathrm{pH}$ declined from 7 to 6.4 on Day 3 and was subsequently constant at an average of pH 6.5 until Day 81. Thus, the chicken eggshell powder effectively retains the fermentation $\mathrm{pH}$. The use of buffer 
made of carbon dioxide/hydrogen carbonate/carbonate can prevent acidification (Deublein and Steinhauser 2008).

\subsection{Reuse of beads intensity in biohydrogen production}

The biohydrogen production of the reused-bead is displayed in Figure 8.

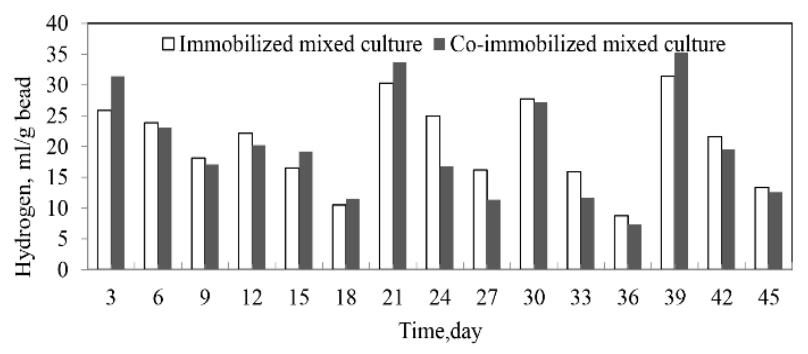

Fig.8. Biohydrogen production using immobilized beads and coimmobilized beads

Figure 8 shows that the biohydrogen gas produced are 1.05 times larger using co-immobilized beads than immobilized beads. Biohydrogen production in both beads visually fluctuated for 15 cycles. These fluctuating biohydrogen yields were similar to those obtained by $\mathrm{Hu}$ et al. (2007).

The biohydrogen production was evidently larger in immobilization beads than in co-immobilization beads on Days $6,9,12,24,27,30,33$ and 36 . The presence of an unfavourable bacterial community structure or mass transfer limitations was assumed to arise from coimmobilized cells. Therefore, bead leakage was further caused microbes to enter into a medium solution for these microbes to consume glucose by reusing immobilization beads, easier than co-immobilization beads (Mesran et al. 2014).

The production of biohydrogen produced by immobilized and co-immobilized mixed culture was relatively stable until 60 days (Figure 8). The stability of the biohydrogen production using immobilized beads was similar to the previous research, where the stable immobilization beads can produce biohydrogen until 60 days (Kumar et al. 1995). Therefore, the immobilized mixed culture could be used repeatedly. The $\mathrm{pH}$ sensitivity from acidic metabolite accumulation for 22 days of fermentation was due to the loss of calcium ions, thereby resulting in transparent, partially broken and soft immobilized mixed culture ( $\mathrm{Hu}$ et al. 2007). The beads become brittle and finally broken down when eroded (Hu et al. 2007).

\section{Conclusion}

The colony growth during the anaerobic fermentation process by reusing immobilized mixed culture beads results in an increase in the number of remarkable colonies by $66 \%$ on Day 9 . The mean weights of the immobilization mixed culture beads for 45 days were 1.78 and $6.45 \mathrm{~g}$, whereas those of the co-immobilization mixed culture beads were 2.1 and $6.46 \mathrm{~g}$. The biohydrogen productions in the immobilization and co-immobilization mixed culture beads were 19.20 and $18.61 \mathrm{~mL} / \mathrm{g}$ bead.

\section{Acknowledgments}

This work was supported by Directorate General of Higher Education, Ministry of Research Technology and Higher Education, Republic of Indonesia through prioritized research colleges. The authors also thank Agung Dian Kharisma as technical personnel.

\section{References}

Akil, K. and Jayanthi, S. (2015), The Biohydrogen Potential of Distillery Wastewater by Dark Fermentation in an Anaerobic Sequencing Batch Reactor, International Journal of Green Energy, 11(1), 28-39.

Alonso, S., Rendueles, M. and Díaz, M. (2015), A Novel Approach to Monitor Stress-Induced Physiological Responses in Immobilized Microorganisms, Applied Microbiology and Biotechnology, 99 (8), 3573-3583.

Cai, J. and Wang, G. (2016), Comparison of Different PreTreatment Methods for Enriching Hydrogen-Producing Bacteria from Intertidal Sludge, International Journal of Green Energy, 13(3), 292-297.

Cheong, D.-Y., Hansen, C.. and Stevens, D. (2006), Production of Bio-Hydrogen by Mesophilic Anaerobic Fermentation in an Acid-Phase Sequencing Batch Reactor, Biotechnology and Bioengineering,96,421-432.

Covarrubias, S.A., De-Bashan, L.E., Moreno, M. and Bashan, Y. (2012), Alginate beads provide a beneficial physical barrier against native microorganisms in wastewater treated with immobilized bacteria and microalgae, Applied Microbiology and Biotechnology,93(6), 2669-80.

Damayanti, A., Sarto, Sediawan, W.B. and Syamsiah, S. (2018), Performance analysis of immobilized and co-immobilized enriched-mixed culture for hydrogen production, Journal of Mechanical Engineering and Sciences, 12(1), 35153528.

Damayanti, A., Sarto, Syamsiah, S. and Sediawan, W.B. (2017), The Influence of Chicken Eggshell Powder As A Buffer on Biohydrogen Production from Rotten Orange (Citrus Nobilis Var. Microcarpa) with Immobilized Mixed Culture, The 3rd International, Vol. 1855, AIP Publishing, In Conference on Engineering, Technology, and Industrial Application (ICETIA), Surakarta, Indonesia, pp. 070006$1-7$.

Das, D. (2009), Advances in biohydrogen production processes: An approach towards commercialization, International Journal of Hydrogen Energy, 34(17), 7349-7357.

Davila-Vazquez, G., de León-Rodríguez, A., AlatristeMondragón, F. and Razo-Flores, E. (2011), The buffer composition impacts the hydrogen production and the microbial community composition in non-axenic cultures, Biomass and Bioenergy, 35(7),3174-3181.

Deublein, D. and Steinhauser, A. (2008), Biogas from Waste and Renewable Resources: An Introduction, WILEY-VCH Verlag GmbH \& Co. KGaA, Weinheim. pp.114.

Dzionek, A., Wojcieszyńska, D. and Guzik, U. (2016), Natural carriers in bioremediation: A review, Electronic Journal of Biotechnology, 23, 28-36.

Hassan, A.F., Abdel-Mohsen, A.M. and Fouda, M.M.G. (2014), Comparative study of calcium alginate, activated carbon, and their composite beads on methylene blue adsorption, Carbohydrate Polymers, 102, 192-8.

$\mathrm{Hu}$, B., Liu, Y., Chi, Z. and Chen, S. (2007), Biological Hydrogen Production Via Bacteria Immobilized in Calcium Alginate Gel Beads, Biological Engineering, 1, 25-37.

Jamali, N.S., Jahim, J.M. and Isahak, W.N.R.W. (2016), Biofilm formation on granular activated carbon in xylose and glucose mixture for thermophilic biohydrogen production, International Journal of Hydrogen Energy, 41(46), 2161721627.

Kumar, A., Jain, S.R., Sharma, C.B., Joshi, A.P. and Kalia, V.C. (1995), Increased H2 production microorganisms by immobilized, World Journal of Mcrobiology \& 
Biotechnology, 11, 156-159.

Lee, K.Y. and Mooney, D.J. (2012), Alginate: Properties and Biomedical Applications, Progress in Polymer Science, 37(1), 106-126.

Luo, G., Xie, L., Zou, Z., Wang, W. and Zhou, Q. (2010), Exploring optimal conditions for thermophilic fermentative hydrogen production from cassava stillage, International Journal of Hydrogen Energy, 35(12), 61616169.

Mesran, M.H., Mamat, S., Pang, Y.R., Hong, T.Y., Muneera-Z, Ghazali, N.F.M., Ali, Md, A., et al. (2014), Preliminary Studies on Immobilized Cells-Based Microbial Fuel Cell System on Its Power Generation Performance, Journal of Asian Scientific Research, 4 (8), 428-435.

Muñoz-Páez, K.M., Poggi-Varaldo, H.M., García-Mena, J., Ponce-Noyola, M.T., Ramos-Valdivia, A.C., BarreraCortés, J., Robles-González, I. V., et al. (2014), Cheese whey as substrate of batch hydrogen production: Effect of temperature and addition of buffer, Waste Management and Research, 32(5), 434-440.

Neunzehn, J., Szuwart, T. and Wiesmann, H.-P. (2015), Eggshells as natural calcium carbonate source in combination with hyaluronan as beneficial additives for bone graft materials, an in vitro study, Head \& Face Medicine, 11:12 (12), 1-10.

Ng, F.L., Phang, S.M., Periasamy, V., Yunus, K. and Fisher, A.C. (2017), Enhancement of Power Output by using Alginate Immobilized Algae in Biophotovoltaic Devices, Scientific Reports, Springer US, 7(1), 1-8.

Penniston, J. and Kana, E.B.G. (2018), Impact of medium pH regulation on biohydrogen production in dark fermentation process using suspended and immobilized microbial cells, Biotechnology and Biotechnological Equipment, 32(1), 204-212.

Reyhani, S.. and Zilouei, H. (2013), Enhanced Biohydrogen Production From Wastewater And The Influence Of Operating Parameters, International Journal of Green Energy, 10, 321-336.

Saripan, A.F. and Reungsang, A. (2014), Thermophilic Fermentative Biohydrogen Production From Xylan by Anaerobic Mixed Cultures in Elephant Dung, International Journal of Green Energy, 12(9), 900-907.

Sekoai, P.T., Awosusi, A.A., Yoro, K.O., Singo, M., Oloye, O., Ayeni, A.O., Bodunrin, M., et al. (2017), Microbial cell immobilization in biohydrogen production: a short overview, Critical Reviews in Biotechnology, 38(2), 1-15.

Sekoai, P.T., Yoro, K.O. and Daramola, M.O. (2016), Batch Fermentative Biohydrogen Production Process Using
Immobilized Anaerobic Sludge from Organic Solid Waste, Environments, 3(4), 38.

Shoichet, M.S., Li, R.H., White, M.L. and Winn, S.R. (1996), Stability of Hydrogels Used in Cell Encapsulation: An In Vitro Comparison of Alginate and Agarose, Biotechnology and Bioengineering, 50, 374-381.

Siahpush, A.R., Lin, J.E. and Wang, H.Y. (1992), Effect of Adsorbents on Degradation of Toxic Organic Compounds by Coimmobilized Systems, Biotechnology and Bioengineering, 39, 619-628.

Singh, L. and Wahid, Z.A. (2014), Methods for enhancing biohydrogen production from biological process: A review, Journal of Industrial and Engineering Chemistry, 21, 7080 .

Sivagurunathan, P., Sen, B. and Lin, C.Y. (2014), Batch fermentative hydrogen production by enriched mixed culture: Combination strategy and their microbial composition., Journal of Bioscience and Bioengineering, 117(2), 222-8.

Smidsrød, O. and Skjåk-Braek, G. (1990), Alginate as Immobilization Matrix for Cells, Trend Biotechnol, 8(3), 71-8.

Wang, S., Ma, Z., Zhang, T., Bao, M. and Su, H. (2017), Optimization and modeling of biohydrogen production by mixed bacterial cultures from raw cassava starch, Frontiers of Chemical Science and Engineering, 11(1), 100-106.

Wu, S.Y., Lin, C.N., Chang, J.S., Lee, K.S. and Lin, P.J. (2002), Microbial hydrogen production with immobilized sewage sludge., Biotechnology Progress, 18 (5), 921-926.

Wu, X., Yao, W. and Zhu, J. (2010), Effect of pH on Continuous Biohydrogen Production From Liquid Swine Manure with Glucose Supplement Using An Anaerobic Sequencing Batch Reactor, International Journal of Hydrogen Energy, 35(13), 6592-6599.

Zhang, C., Kang, X., Liang, N. and Abdullah, A. (2017), Improvement of Biohydrogen Production from Dark Fermentation by Cocultures and Activated Carbon Immobilization, Energy and Fuels, 31(11), 12217-12222.

Zhu, H., Parker, W., Basnar, R., Proracki, A., Falletta, P., Béland, M. and Seto, P. (2009), Buffer requirements for enhanced hydrogen production in acidogenic digestion of food wastes, Bioresource Technology, 100(21), 5097-5102.

Zohar-Perez, C., Chet, I. and Nussinovitch, A. (2004), Unexpected distribution of immobilized microorganisms within alginate beads, Biotechnology and Bioengineering, 88(5), 671-674. 